\title{
INICIAÇÃO À DOCÊNCIA EM TEMPOS DE PANDEMIA: UMA IMERSÃO NAS REDES SOCIAIS PARA O ENSINO DE CIÊNCIAS
}

\author{
INITIATION TO TEACHING IN TIMES OF PANDEMIC: AN Immersion IN SOCIAL \\ NETWORKS FOR SCIENCE TEACHING
}

\section{Lucas Guimarães}

Instituto Federal do Rio de Janeiro, Rio de Janeiro, RJ, Brasil. E-mail: lucaspegui@hotmail.com

\section{Ivanete da Rosa Silva de Oliveira}

Centro Universitário de Volta Redonda, Volta Redonda, RJ, Brasil. E-mail: ivanete.oliveira@unifoa. edu.br

\section{Ana Paula Cunha Pereira}

Centro Universitário de Volta Redonda, Volta Redonda, RJ, Brasil. E-mail: ana.cunha@unifoa.edu.br

\section{Gabriella Teixeira Schuwarte}

Centro Universitário de Volta Redonda, Volta Redonda, RJ, Brasil E-mail: gtschuwarte@outlook.com

\section{Henrique Candido}

Centro Universitário de Volta Redonda, Volta Redonda, RJ, Brasil E-mail: lucaspegui@hotmail.com

DOI: https://doi.org/10.46550/amormundi.v2i6.122

Recebido em: 06.10.2021

Aceito em: 20.10.2021

\begin{abstract}
Resumo: Dentre as Políticas Públicas Educacionais, o Programa Institucional de Bolsa de Iniciação à Docência (PIBID) é uma das que mais se destaca com práticas exitosas desenvolvidas na escola pública, sendo considerado por muitos graduandos como um processo disruptivo quando se trata da construção da identidade docente. Contudo, a pandemia da COVID-19 modificou a rotina escolar profundamente e demonstrou limites que atingiram todas as instâncias, inclusive o PIBID. Esse trabalho tem como principal objetivo relatar os caminhos percorridos por um grupo de licenciandos em Ciências Biológicas para desenvolver açóes do PIBID voltadas para estudantes de escolas públicas durante o período pandêmico. As redes sociais, bem como os recursos tecnológicos, foram muito necessárias para fortalecer as relaçôes sociais impactadas pelo isolamento, como também, se tornaram veículos de disseminação de fakes-news, provocando discussões e debates de pesquisadores acerca de sua efetividade na aprendizagem. Essas implicaçóes levaram os pibidianos de Biologia a criar uma conta de Instagram, para aliar o processo ensino-aprendizagem com a distância do Ensino Remoto em tempos de pandemia. Foram produzidos conteúdos para essa rede social visando a Alfabetização Científica de estudantes da Educação Básica de Escolas Públicas e do público em geral.
\end{abstract}

Palavras-chave: Ensino de ciências. Escola Pública. PIBID. Tecnologia. 


\begin{abstract}
Among the Public Educational Policies, the Institutional Program for Teaching Initiation Scholarship (PIBID) is one of the most prominent with successful practices developed in public schools, being considered by many undergraduates as a disruptive process when it comes to the construction of the teaching identity. However, the COVID-19 pandemic has profoundly changed the school routine and has shown limits that have affected all instances, including the PIBID. The main objective of this work is to report the paths taken by a group of Biological Sciences undergraduate students to develop PIBID actions aimed at public school students during the pandemic period. Social networks, as well as technological resources, were very necessary to strengthen social relationships impacted by isolation, and also became vehicles for the dissemination of fakes-news, provoking discussion and debate among researchers about their effectiveness in learning. These implications led the Biology pibidians to create an Instagram account, to ally the teaching-learning process with the distance of Remote Teaching in times of pandemic. Contents were produced for this social network aiming at the Scientific Literacy of Basic Education students from Public Schools and the general public.
\end{abstract}

Keywords: Science Teaching; Public School; PIBID; Technology

\title{
Introduçáo
}

Programa de Institucional de Bolsas de Iniciação à Docência (PIBID), começou a ser elaborado a partir de uma ação coletiva do Ministério da Educaçáo (MEC), Secretaria de Educação Superior (SESu), Coordenação de Aperfeiçoamento de Pessoal de Nível Superior (CAPES) e do Fundo Nacional de Desenvolvimento da Educação (FNDE), com a proposta de fomentar a formação docente nas Instituiçóes de Ensino Superior.

Instituído em 2007 somente para universidades públicas, em 2013 foi ampliado e passou a ser desenvolvido por instituiçóes privadas, abrangendo já em 2014 mais de 100.000.000 bolsistas entre estudantes de licenciaturas, docentes da educação superior e da educação básica (CAPES, 2015).

Desse modo, cabe ressaltar que, após um tempo de ação do PIBID em diversas escolas públicas no Brasil, pode-se observar que os bolsistas de iniciação à docência, acabam vivenciando experiências antecipadas desde os momentos iniciais do curso, o que contribui para a formação inicial docente (STANZANI, 2012).

No entanto, em 2020, devido o início do período pandêmico da COVID19, os processos de ensino-aprendizagem de todas as escolas brasileiras sofreram alteraçóes. A realidade da pandemia forçou uma mudança na rotina e dinâmica escolar que, impedidas de funcionar de modo presencial, tiveram que aliar-se às redes sociais para continuar ofertando a educação. Esse novo cenário promoveu uma revisão nos paradigmas escolares. Como exemplo, pode-se citar o fato de que, desde 2008, existe uma lei Estadual do Governo do Rio de Janeiro que proíbe o uso de celulares em sala de aula, ou seja, o que era considerado como um "impeditivo à aprendizagem", tornou-se o único recurso possível nesse momento para ensinar e aprender.

Diante do caos atual na sociedade, a escola precisou tornar-se remota e invadir os lares dos estudantes com os responsáveis - pais ou outros familiares - assumindo a função de mediadores do processo de ensino-aprendizagem. No entanto, deve-se considerar que nem todos os lares são estruturados fisicamente para ser funcionar como um polo educativo. Como também, muitas famílias não possuem condiçôes técnico-pedagógicas para dar suporte e acompanhar os estudantes nesta proposta remota

Diante do exposto, torna-se desafiador para o professor pensar em estratégias de ensino que 
sejam atrativas e que causem engajamento de estudantes da Educação Básica para proporcionar aprendizagem aos alunos nesse momento de imprevisibilidade.

No decorrer da história a inserção de artefatos tecnológicos promoveram mudanças à sociedade de forma geral. Contudo, em relação à instituição escolar, essas modificaçôes ainda eram incipientes. Silva (2011) alerta que em relação à tecnologia, apesar da inserçáo de programas com novas roupagens, a educaçáo continuou a mesma que a do século passado, pois as mudanças curriculares que articulam o uso de tecnologias não possuem a participação dos docentes envolvidos no processo, tornando-as vulneráveis e facilmente descontinuadas.

Assim, não seria leviano afirmar que se uma pessoa fosse isolada em 1970 em um determinado local sem contato como a sociedade e voltasse a ser reintegrada em 2020, constataria que ocorreu significativas mudanças na sociedade em função da tecnologia. No entanto, ao chegar à escola, veria que a dinâmica das instituiçóes de ensino, em sua maioria, continua a mesma.

Baseado nesses fatores, e na busca de aprimoramento e fundamentação do PIBID, esse estudo irá buscar responder a seguinte questão: Como as redes sociais podem auxiliar na iniciação à docência em tempos de pandemia?

O principal objetivo dessa investigação foi evidenciar estratégias de ensino de ciências que possibilitassem a aprendizagem de estudantes da educação básica no período pandêmico. Para tal, pretende-se: refletir sobre a relação entre tecnologia e docência na pandemia; analisar como estudantes de iniciaçáo à docência podem utilizar a rede social como recurso didáticopedagógico.

Esse trabalho foi realizado no âmbito de uma Instituição de Ensino Superior privada sem fins lucrativos do Sul Fluminense, com a participação de 10 licenciandos em Ciências Biológicas que integravam o PIBID e que são supervisionados por docentes da Educaçáo Básica e Superior.

\section{Tecnologia, pandemia e docência na Educaçáo Básica}

A sociedade atual vive um período de pandemia que tem desgastado a toda população mediante o fato de perdas que assolam todo o país, como de entes queridos, das relaçóes sociais em meio físico, de ordem econômica etc. A escola também sofreu grandes mudanças desde o início do contágio com o vírus SARS-COV-2, e desse modo, necessitou ser repensada e ganhar um novo significado nas impossibilidades que o contexto pandêmico impôs. Ressalta-se que o momento vivido foi caracterizado por informaçôes que foram disseminadas de maneira instantânea, com temas emergentes controversos, que envolvem fenômenos como a Fake News que por estarem cada vez mais presentes no nosso dia a dia, reforçam a necessidade da propagação de uma educação crítica, que não fique restrita ao espaço escolar.

A comunicação para um público amplo tem sido fundamentada no desenvolvimento das tecnologias, mais especificamente pelas Tecnologias Digitais de Informação e Comunicação (TDIC), as quais conduzem a novos contextos de produção de aulas, novas formas de relação, de modos de viver, pensar e agir diferenciados de outros tempos. Segundo Almeida e Valente (2005, p. 8) as TDIC "impóe mudanças nos métodos de trabalho dos professores, gerando modificaçóes no funcionamento das instituiçóes e no sistema educativo".

A prática pedagógica deve privilegiar a construção colaborativa e coletiva dos 
conhecimentos e o uso dos artefatos tecnológicos que possibilitam experiências diferenciadas de ensino e aprendizagem, na qual o professor atua como mediador e orientador e o estudante assume um papel mais ativo neste processo.

Desse modo, a tecnologia não pode ter um fim em si mesma, e sim, ser um recurso que possibilite o processo de ensino-aprendizagem. A utilizaçáo das TDIC nas aulas pode contribuir para ressignificar a educação. Dentre as prerrogativas que fortalecem essa assertiva, pode-se destacar: a possibilidade de a aula ser mais atrativa, promovendo maior interação e trabalho colaborativo entre estudantes e professores e proporcionando melhorias no processo de ensinoaprendizagem.

A inserção das TDIC pode contribuir muito no processo de ensino- aprendizagem, tendo em vista que estimula a colaboração, pois atua numa perspectiva em que ocorre uma exploração efetiva e criativa dos recursos baseados no TDIC. Para um total aproveitamento das suas vantagens a utilização das TDIC em sala de aula, deve sempre vir precedidas de planejamento adequado, de uma prática educativa centrada no estudante, de professores atualizados e principalmente de um currículo receptivos às inovações (ALMEIDA, 2004).

\section{PIBIDBIOFOA: a rede social para divulgar ciências}

O início do PIBID no ano de 2020 foi muito conturbado e incerto, houve inicialmente um momento em que a Coordenação de Aperfeiçoamento de Pessoal de Nível Superior (CAPES), instituiçáo do Governo Federal que financia o programa, adiou por alguns meses o seu início pelo fato das escolas públicas de todo país estarem fechadas. Essa notícia surpreendeu toda a equipe formada por coordenadores institucionais, professores supervisores e estudantes bolsistas, que já havia sido selecionada, gerando conturbaçóes para o momento de início das açóes pela instituição e pela escola receptora dos licenciandos.

Para enfrentar essa situação tão adversa, a primeira estratégia foi realizar uma reunião entre todos os atores e refletir sobre os impactos que tal realidade poderia trazer para sociedade, de forma geral, e para a educação de forma específica. Em um debate surgiu a temática de como as redes sociais tinham se tornado um espaço nocivo, pois incomodava a todos os envolvidos no projeto pela grande quantidade de Fake News que muito atrapalhava e distorcia os conceitos científicos que deveriam ser bem compreendidos durante a pandemia.

Decidiu-se, desse modo, pela construção de uma estratégia de ensino que usasse as redes sociais para promover o engajamento de estudantes da Educaçáo Básica e, principalmente, contribuir para a Alfabetização Cientifica da população.

Consideramos alfabetização científica assim como Chassot (2003, p.91) que afirma que "a alfabetização científica pode ser considerada como uma das dimensôes para potencializar alternativas que privilegiam uma educação mais comprometida". Chassot defende a alfabetização científica e amplia ainda mais a sua importância como destacado por ele:

seria desejável que os alfabetizados cientificamente não apenas tivessem facilitada leitura do mundo em que vivem, mas entendessem as necessidades de transformálo - e, preferencialmente, transformá-lo em algo melhor. Tenho sido recorrente na defesa da exigência de com a ciência melhorarmos a vida no planeta, e não tornála mais perigosa, como ocorre, às vezes, com maus usos de algumas tecnologias (CHASSOT, 2003, p.94). 
No entanto, um desafio se interpunha: como utilizar uma linguagem que se adaptasse a diferentes contextos, que são muito presentes nas redes sociais, para realizar a decodificaçáo dos conteúdos?

Foram os licenciados que escolheram qual seria a rede social, no caso, o Instagram ${ }^{1}$ e o símbolo da página (Figura 1), que mais tarde veio a se tornar a marca do PIBIDBIOFOA.

Figura 1: símbolo elaborado pelos alunos para a divulgação científica nas redes sociais

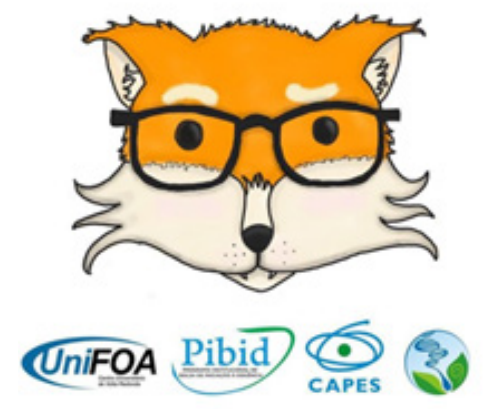

Fonte: autoria própria (2020)

Em seguida a esse momento de elaboração, iniciou-se um planejamento das açóes que seriam iniciadas de acordo com que o Instagram fornece. Para a ferramenta das postagens foi pensado em posts que abordavam a regiáo Sul Fluminense como a fauna e a flora da Floresta da Cicuta, resquício de Mata Atlântica da nossa regiáo (Figura 2).

Essa abordagem surgiu da necessidade que os discentes tinham de divulgar e sensibilizar para a importância da preservação da Floresta da Cicuta. Foi considerado relevante tratar do fragmento de Mata Atlântica da nossa região pelo fato dos graves danos respiratórios causados pelo coronavírus e a péssima qualidade do ar de nossa cidadá. Um dos estudantes relatou: "temos um pouco de Mata Atlântica que morre a cada dia, e uma grande empresa, a Companhia Siderúrgica Nacional (CSN), que polui o nosso ar, prejudicando a população e nada é feito em relação ao passivo ambiental". Todos os licenciandos concordaram que a CSN prejudica muito a cidade e que deveria ser mencionado o valor da floresta da Cicuta.

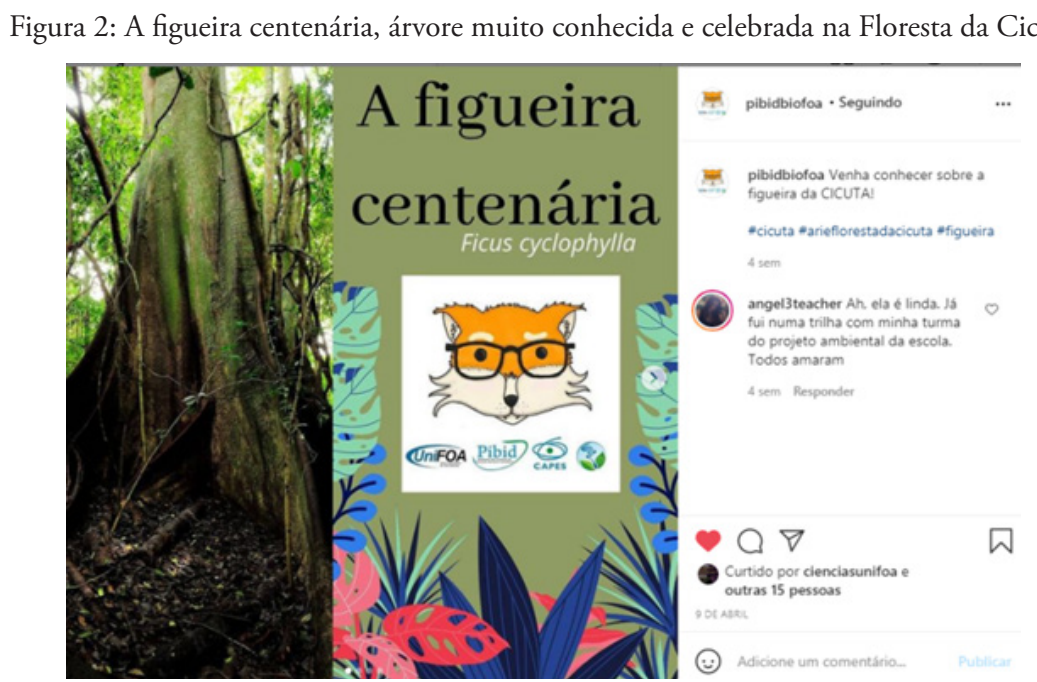

Fonte: Disponível em: https://www.instagram.com/p/CNc5qFOnZ_j/ Acesso em 11 de maio de 2021

1 https://www.instagram.com/pibidbiofoa/ 
A eficácia das redes sociais na ampliação de atuação do PIBID mostra-se através desse post, em que retrata a interação feita por uma professora de ciências da Rede Municipal da região que usou o material produzido como recurso didático-pedagógico para ensinar e sensibilizar sobre a preservação da Floresta da Cicuta em suas aulas.

Também foram planejadas postagens que visavam atrair fấs de animes explorando a sua relação com a ciência estabelecendo assim um diálogo com o público do anime Naruto, que é amplamente conhecido entre os adolescentes, faixa etária foco da nossa ação.

As postagens com essa temática tiveram grande repercussão, atingindo o público adolescente e outras faixas etárias, que não imaginávamos que atingiríamos, e que, inclusive, deram uma maior motivaçáo para os estudantes da escola em que o PIBID estava imerso, tendo em vista que os licenciandos do PIBID começaram a interagir com os discentes da escola que atendiam através dos comentários, principalmente de postagens que utilizavam esse personagem.

Um outro tipo de postagem que gerou muito engajamento nas redes sociais (views, likes e comentários) foram os chamados reels. Vídeos curtos de 30 segundos que levavam muita informação de qualidade científica na página do Instagram. Foram feitos 6 vídeos nessa modalidade denominada de reels com 10.350 visualizaçôes com temas do cotidiano, como maquiagem (figura 4), plantas, doenças relacionadas com séries aclamadas de TV.

Figura 3: Reels com o tema sobre maquiagem com interação de alunos e público em geral

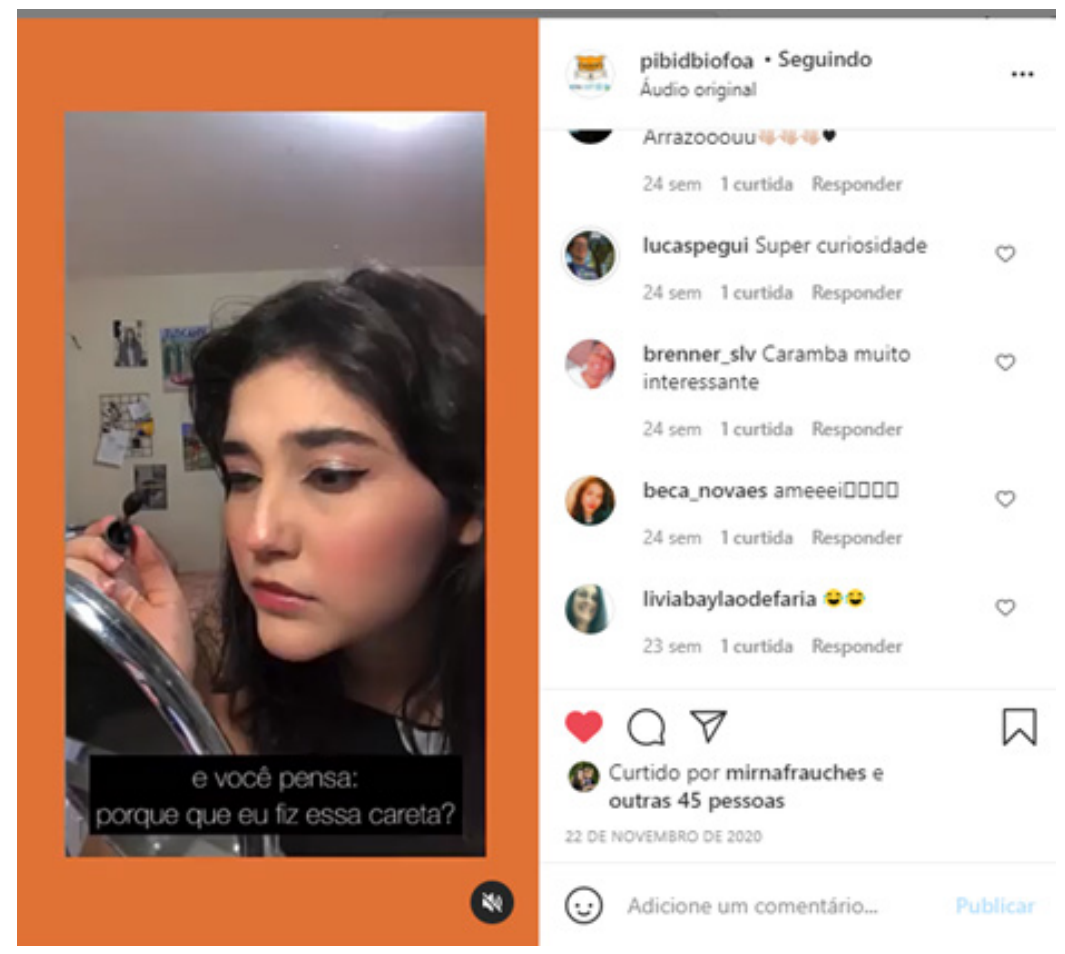

Disponível em: https://www.instagram.com/reel/CH51NunnOnp/ Acesso em 11 de maio de 2021

O desenvolvimento das atividades de ensino por meio da rede social se mostrou como lócus de ampliação para divulgar ciências durante a pandemia da COVID-19. É importante mencionar que o PIBID é uma política pública que pode ir além do espaço escolar, a pandemia nos mostrou isso, a necessidade de expandir as fronteiras do processo de ensino-aprendizagem. 


\section{Consideraçóes finais}

A pandemia do COVID-19 vem mostrando cada vez mais as desigualdades da sociedade brasileira, e até mesmo no mundo, seus impactos são duros e evidentes em múltiplas dimensões, e principalmente na educação, torna-se cada vez mais palpável o seu impacto negativo na busca do desafio de promover uma educação com equidade e universal.

Os educadores vêm debatendo o impacto da pandemia na educaçáo, constatando que ainda permaneceremos muito tempo com o vírus descontrolado impactando famílias do mundo inteiro, causando marcas na alma que provocam um estado permanente de luto, o que irá influenciar durante muito tempo na escola, mas cabe ressaltar que esses resultados não são irreversíveis, a rede social que esse trabalho trouxe, nos mostra o potencial para o aprendizado em Ciências em diversos meios.

Por mais que o PIBID não tenha tido tempo de mensurar o seu impacto na identidade docente, cabe mencionar que esse atual momento de pandemia que vivemos é único e aproximar os licenciandos desse desafio atual, os aproximará dessa nova escola que está se desenhando, em que o professor precisa assumir uma nova postura mediante a essa nova maneira de ensinar e aprender.

Desse modo, constatou-se que a tecnologia pode ser uma grande aliada para valorização da docência nesse momento de pandemia, inclusive, divulgando conteúdos que possuem abordagem científica com o intuito de contribuir para a alfabetização crítica frente à ciência.

O Instagram, rede social escolhida como instrumento de aproximação entre licenciandos em Ciências Biológicas e estudantes da Educação Básica, se mostrou como uma potente via para promover a aprendizagem. Nessa perspectiva, aprende quem faz, quem vê, quem interage, quem acessa, quem supervisiona etc. Ou seja, todos os atores envolvidos nessa prática colaborativa da docência aprimoram suas competências e habilidades que vão para além das digitais e tecnológicas, pois requerem outras competências para a docência, envolvendo até mesmo as socioemocionais.

A relevância do processo de ensino do PIBID através das redes sociais mostrou-se relevante no que se diz respeito a esse espaço, que, muitas vezes, é táo mal ocupado. Em tempos de pandemia em que muitos lives foram feitas, podemos observaros acadêmicos de "alta patente" achavam esse espaço fútil e sem importância, admitindo que com os desafios impostos pelo vírus, pode-se perceber que até esses que estavam distante tiveram que criar redes de diálogos nesses canais.

\section{Referências}

ALMEIDA, F. J.; VALENTE, J. A.. Visão Analítica da Informática na Educação no Brasil. A Questáo da Formaçáo do Professor, 2005.

ALMEIDA, M. E. B. de. Gestão de tecnologias, mídias e recursos na escola: o compartilhar de significados, Em Aberto, Brasília, v. 22, n. 79, p. 75-89, jan. 2004. Disponível em: http:// www.rbep.inep.gov.br/index.php/emaberto/article/viewFile/1435/1170. Acesso em: 12 abril 2021.

CAPES. Coordenação de Aperfeiçoamento de Pessoal de Nível Superior. Relatório de gestáo 
do exercício de 2014. Brasília, 2015. disponível em: https://www.gov.br/capes/pt-br/centraisde-conteudo/2014_Relatorio_de_Gestao_CAPES.pdf. Acesso em: 12 abril 2021.

CHASSOT, A, . Alfabetização científica: uma possibilidade para a inclusão social. Rev. Bras. Educ. [online]. 2003, n.22, p.89-100. Disponível em: http://www.scielo.br/pdf/rbedu/n22/ n22a09.pdf. Acesso em: 02 ago. 2021.

KENSKI, V. M. Educação e tecnologias: O novo ritmo da informação. Campinas, SP: Papirus, 2007.

SILVA, Ângela Carrancho da. Educaçáo e tecnologia: entre o discurso e a prática. Ensaio: aval.pol.públ.Educ., Rio de Janeiro, v. 19, n. 72, p. 527-554, Sept. 2011. Didponível em: $<$ http://www.scielo.br/scielo.php?script=sci_arttext\&pid=S0104-40362011000400005\&ln $\mathrm{g}=\mathrm{en} \& \mathrm{nrm}=\mathrm{iso}>$. Acesso em: 13 abril 2021. https://doi.org/10.1590/S010440362011000400005 .

STANZANI, E. L. O papel do PIBID na formaçáo inicial de professores de química na Universidade Estadual de Londrina. 2012. 86 f. Dissertação (Mestrado em Ensino de Ciências e Educação Matemática) - Universidade Estadual de Londrina, Londrina, 2012. 